\title{
Article \\ Cumulative Shear Damage Mechanism to Short Fiber Type C/SiC
}

\author{
Yuta Tobata ${ }^{1} \mathbb{D}$, Shinsuke Takeuchi ${ }^{2}$ and Ken Goto ${ }^{2, *}$ \\ 1 Department of Space and Astronautical Science, SOKENDAI, 3-1-1, Yoshinodai, Chuo-ku, \\ Sagamihara 252-5210, Japan; tobata.yuta@ac.jaxa.jp or yuta.tobata@community.isunet.edu \\ 2 Japan Aerospace Exploration Agency (JAXA), 3-1-1, Yoshinodai, Chuo-ku, Sagamihara 252-5210, Japan; \\ takeuchi@svs.eng.isas.jaxa.jp \\ * Correspondence: goto.ken@jaxa.jp
}

Citation: Tobata, Y.; Takeuchi, S.; Goto, K. Cumulative Shear Damage Mechanism to Short Fiber Type C/SiC. J. Compos. Sci. 2021, 5, 230. https://doi.org/10.3390/jcs5090230

Academic Editors: Francesco Tornabene and Gérard L. Vignoles

Received: 25 June 2021

Accepted: 30 July 2021

Published: 30 August 2021

Publisher's Note: MDPI stays neutral with regard to jurisdictional claims in published maps and institutional affiliations.

Copyright: (c) 2021 by the authors. Licensee MDPI, Basel, Switzerland. This article is an open access article distributed under the terms and conditions of the Creative Commons Attribution (CC BY) license (https:// creativecommons.org/licenses/by/ $4.0 /)$.

\begin{abstract}
A cumulative damage mechanism for short fiber type $\mathrm{C} / \mathrm{SiC}$ during shear loadingunloading testing was examined and quantified using Iosipescu specimens parallel in the in-plane and through-thickness plane, and by using modified fracture and damage mechanics theory referring to measured damage characteristics (crack length, number and angle). A nonlinear stress-strain relation was found for both specimens. Decrease in the apparent modulus was confirmed with increased peak stress, although permanent strain increased. Inelastic strain of the decomposed tensile direction derived from shear stress was greater than that of the compressive one. Cracks propagated perpendicularly to the tensile direction, intruding on the boundary of the transverse fibers and connecting to other cracks. The theoretical damage mechanics model succeeded to predict the stress-strain relation, proposing that the shear mechanical properties are predictable by measuring the damage characteristics.
\end{abstract}

Keywords: CMC; crack propagation process; cumulative damage mechanism; damage mechanics model; mechanical property; shear; short fiber

\section{Introduction}

Short carbon fiber-reinforced silicon carbide (short fiber type $\mathrm{C} / \mathrm{SiC}$ ) has been applied to brake disks of high-performance automobiles because of its superior light weight and moderate hot wear properties compared to cast iron [1-4]. The material is also anticipated for use in fusion reactors and space telescope applications because of its low and isotropic thermal expansion coefficient $[5,6]$.

Nevertheless, the only application of short fiber type $\mathrm{C} / \mathrm{SiC}$ to have succeeded is that in automobiles. One possible reason for this marked lack of wider use is apparently because of the lack of knowledge of cumulative damage behavior and mechanisms, which must be elucidated for damage-tolerant design, as they were for the continuous fiber type ceramic matrix composite (CMC) $[7,8]$. Randomly dispersed fibers and thermal process cracks caused by sintering and cooling processes disturb the pursuit of newly propagated cracks.

Aiming at expanded usage, the authors conducted loading-unloading tests under monotonic compression and tension $[9,10]$. The investigations revealed that the apparent modulus (referring to the slope between the points of peak stress and the end of unloading of each cycle) decreased concomitantly with increased peak stress, whereas permanent strain increased, as in the case of continuous fiber type CMC [11]. However, the unloading modulus (referring to the tangent of stress-strain curve in unloading) did not change. Observation of crack propagation processes suggests that this reason is the lack of fiber fracture and crack propagation between transverse fibers. To explain the relation between mechanical properties and damage characteristics such as crack length, number and inclination to the loading direction, a damage mechanics model was proposed to predict 
stress-strain relations, considering the crack opening, and closed inside crack friction only in the case of compression. Results show that this model can roughly estimate the stress-strain relation.

Regarding the shear stress condition, Shi et al. investigated mechanical properties of the in-plane using Iosipescu testing and asymmetric four-point bending (AFPB) testing [12]. The report revealed that the values of the shear modulus and yield stress of each test methods are close. In addition, this study calculated the stress distribution around the Vnotch using FEM analysis for verifying the validity of both test methods. Results show that an acceptable stress concentration was achieved around the notch. Surface observations of specimens after fracture revealed crack propagation near the notch, locally oriented by the longitudinal fiber bundle across the matrix area, the interface between fiber and matrix or within the fiber bundle. However, cumulative damage behavior was not revealed.

In the case of continuous fiber type $\mathrm{C} / \mathrm{SiC}$, Jain et al. proposed a damage model [13] based on the method by Barbero [14] and quantified damage parameters, which forecasts overall fracture by applying Tsai-Wu failure criterion [15]. This model is effective to predict the failure from the load history precisely. Jun et al. also conducted finite element analysis to predict stress-strain behavior of off-axis tension-compression test by fitting damage parameters according to continuous damage mechanics [16].

On the other hand, in real operation, an unexpected load can be conducted, which makes it difficult to predict precisely and requires complemental data that can predict the actual damage condition. Considering nondestructive health monitoring techniques for hot gas components in a gas turbine [17], damage-tolerant crack length should be defined. Therefore, it is a significant issue to reveal the relation between crack growth and mechanical properties quantitively for predicting fracture.

In terms of this, Santhosh et.al. proposed a unit cell model of ceramic matrix composite, considering fiber matrix interfacial debonding and friction under multiaxial loading and predicted shear stress-strain behavior [18]. This useful model, however, only targets the cross-ply laminates. Meanwhile, fibers of short fiber type $\mathrm{C} / \mathrm{SiC}$ do not regularly align $[9,10]$ and thereby the previous damage mechanics model is not applicable. Therefore, the cumulative mechanism under shear loading of short fiber type CMC is expected.

The current study was conducted to propose damage mechanics model of short fiber type $\mathrm{C} / \mathrm{SiC}$ that can predict mechanical response under shear loading from observed damage characteristics.

\section{Materials and Methods}

\subsection{Materials}

Short fiber type C/SiC was produced by Coorstek KK, Tokyo, Japan, which shapes a disk (240 $\mathrm{mm}$ diameter, $10 \mathrm{~mm}$ thickness) undergoing a curing press under one-directional pressure silicon infiltration sintering. Pitch-based carbon fiber was used as a reinforcement (DIALEAD $^{\circledR}, \mathrm{K}-223 \mathrm{HG}$, Mitsubishi Chemical Inc., Tokyo, Japan). The number of filaments in a fiber bundle is 12,000 . Fibers were two-dimensionally directed perpendicularly to the press direction; the longitudinal fiber bundles were randomly dispersed in one plane, whereas the transverse fiber bundles could be confirmed in the orthogonal plane, as shown in Figure 1. Hereinafter, the former plane is designated as "in-plane". The latter plane is designated as the "through-thickness plane". The material mainly contains carbon fiber bundles, which are similar to a unidirectional carbon-carbon composite because fibers are connected with carbon phase. However, some silicon carbide and silicon exist through the silicon infiltration sintering. During the sintering and cooling process, non-negligible quantities of process-cracks initiated. The fiber content is less than $30 \%$. The maximum fiber length is $6 \mathrm{~mm}$. The fiber diameter is $11 \mu \mathrm{m}$. Additional details have been referred from reports of earlier studies [9,10,19-21]. 


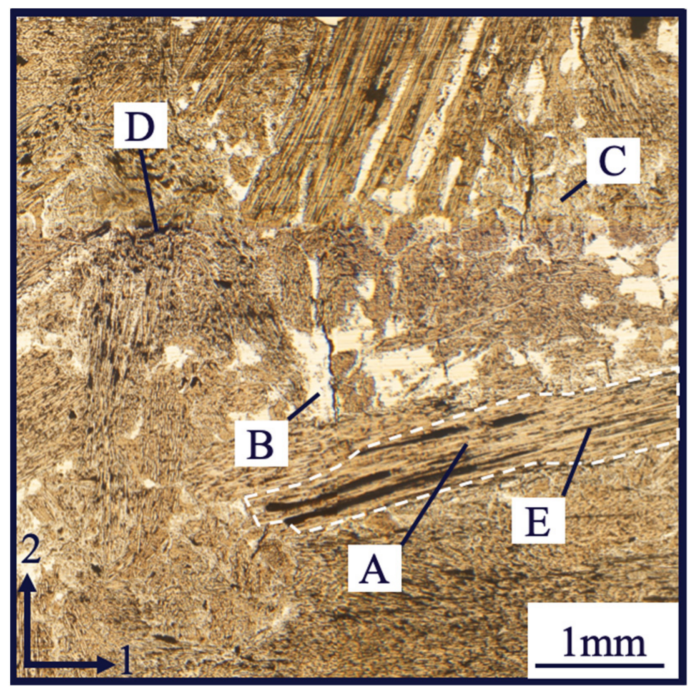

(a)

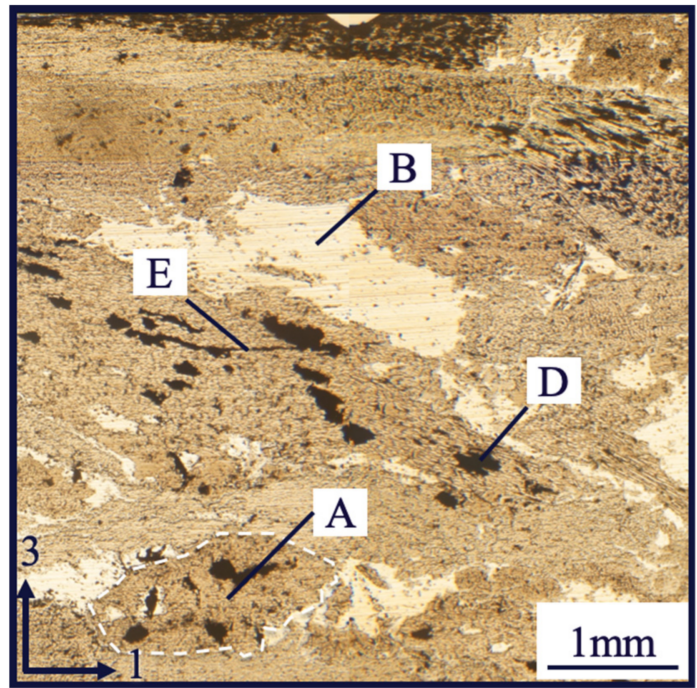

(b)

Figure 1. Optical microscope surface image of macro features of the specimen: (a) in-plane (A, fiber bundle; B, Si phase; $\mathrm{C}, \mathrm{SiC}$ phase; $\mathrm{D}$, pore; E, process-crack); (b) through-thickness plane (the figure shows characters identical to those of the in-plane surface image.).

\subsection{Shear Loading Test}

The Iosipescu specimen was prepared for crack observations of both the in-plane and through-thickness plane, as shown in Figure 2. The SUS spacers were only attached on through-thickness specimens to set them on the test jig, as shown in Figure 3. Specimens were cut randomly and separately so that the through-thickness direction accords with three directions, which is the same as the pressure direction during curing. Accordingly, in-plane was defined as the 1,2 plane, whereas the loading direction was defined as the 1 direction.

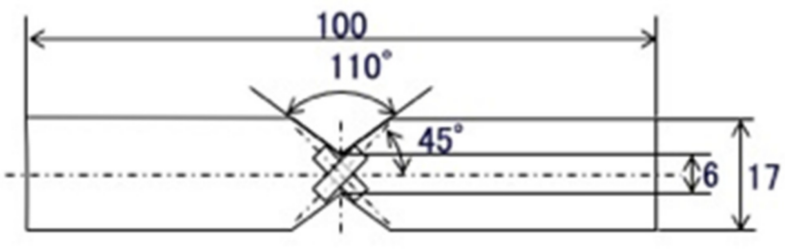

(a)

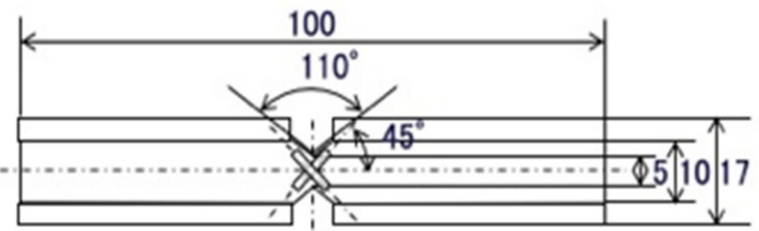

(b)

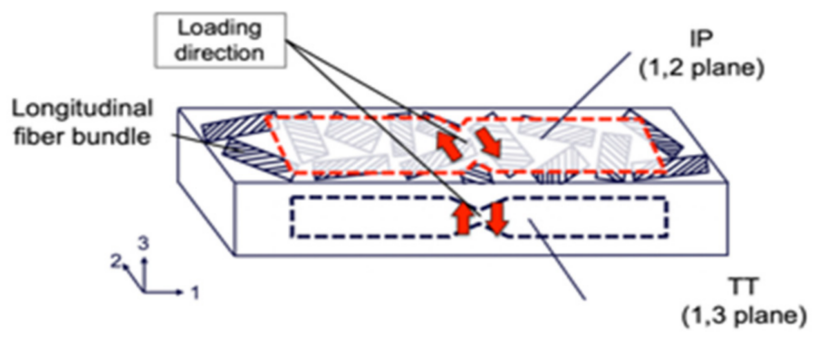

(c)

Figure 2. Dimensions of the specimens and the coordinate system. (a) Dimensions of the in-plane Iosipescu specimen. The specimen thickness is $5 \mathrm{~mm}$. (b) Dimensions of the through-thickness plane Iosipescu specimen. The specimen thickness is $5 \mathrm{~mm}$. Four SUS tabs were attached to set jig parts with proper width. (c) Coordinate system: 1,2 plane is in-plane and 1,3 plane is the through-thickness plane. The three directions accord with the press direction during the curing process. 


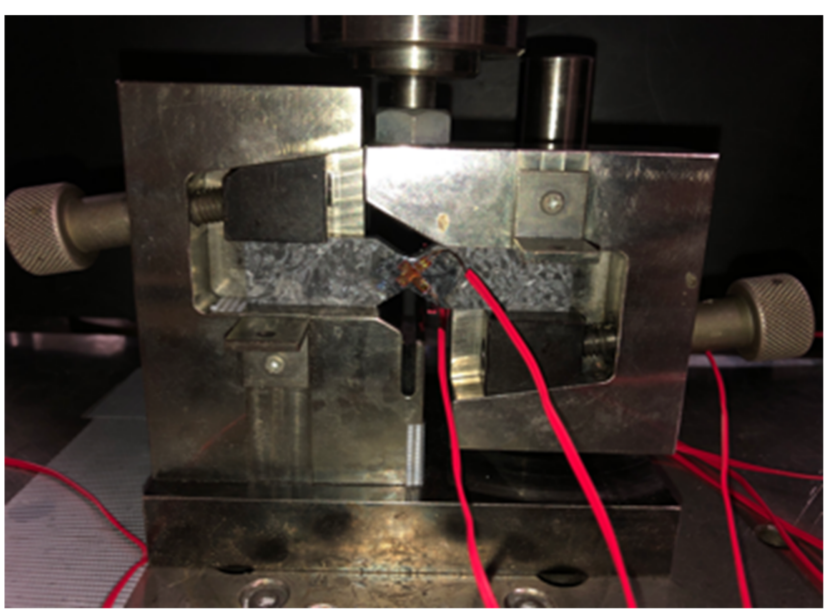

(a)

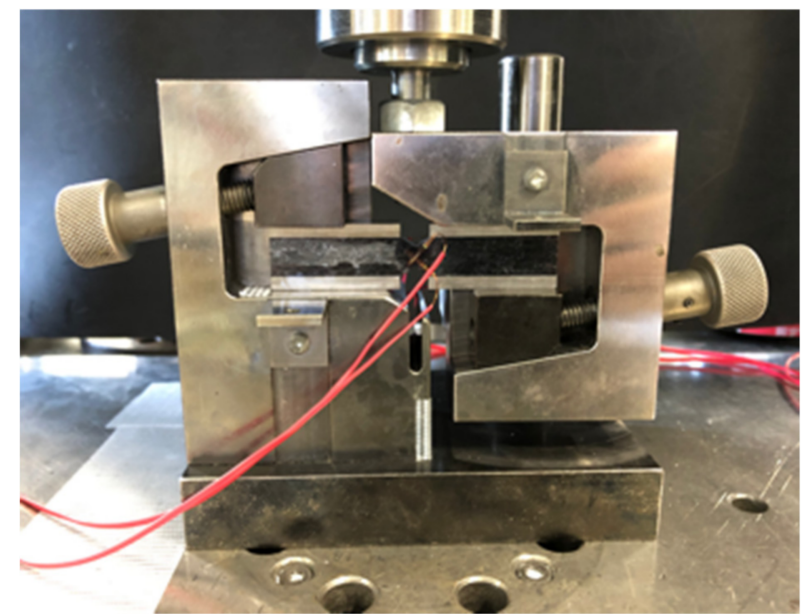

(b)

Figure 3. Configuration of shear loading test. (a) Shear loading test of In-plane specimens; (b) shear loading test of through-thickness plane specimens. All of the specimens were fixed on the specific SUS jig and loaded by pressing the universal testing from the top so that shear load is conducted in the center of specimen.

Shear loading tests and loading-unloading tests were conducted using a universal testing machine (Autograph AG-10; Shimadzu Corp., Kyoto, Japan). Three samples were prepared for each test. Unloading was conducted at $10 \mathrm{MPa}, 15 \mathrm{MPa}, 20 \mathrm{MPa}$ and $25 \mathrm{MPa}$ for the through-thickness plane specimen, and at $10 \mathrm{MPa}, 15 \mathrm{MPa}, 20 \mathrm{MPa}, 25 \mathrm{MPa}, 30 \mathrm{MPa}$, $40 \mathrm{MPa}, 50 \mathrm{MPa}$ and $60 \mathrm{MPa}$ for the in-plane specimen (hereinafter "peak stress"). The stroke speed was $0.02 \mathrm{~mm} / \mathrm{min}$. Four strain gages were attached on each specimen. Two strain gages were attached on each plane, placed orthogonally with $45^{\circ}$ inclinations to the central axis of specimens, as shown in Figure 2. Strain gages of two types were prepared to attach correctly on each specimen (in-plane: $5 \mathrm{~mm}$ gage length, KFGS-5-120-C1-11; Kyowa Electronic Instrument Co. Ltd., Tokyo, Japan, through-thickness-plane: $4 \mathrm{~mm}$ gage length, KFGS-4-120-C1-11; Kyowa Electronic Instrument Co. Ltd., Tokyo, Japan). We measured shear strain $\gamma$ by adding the absolute strain value of each direction (tensile direction, $\varepsilon^{+} \varepsilon^{+}$; compressive direction, $\varepsilon^{-}$) as described in the following Equation.

$$
\gamma=\varepsilon^{+}+\left|\varepsilon^{-}\right|
$$

During the loading-unloading test, we measured the unloading modulus $G_{u}$ calculated using the following Equation.

$$
G_{u}=\frac{\tau_{p}}{\gamma\left(\sigma_{p}\right)-\gamma\left(\tau_{p}-\tau_{g}\right)}
$$

Therein, $\tau_{p}$ signifies the peak stress; $\tau_{g}$ is the $10 \mathrm{MPa}$ gap from peak stresses following the method described in a report of an earlier study [8,9]. The cumulative strain after unloading was measured as permanent strain $\gamma_{0}$. The apparent modulus was measured by calculating the following equation:

$$
G^{*}=\frac{\sigma_{p}}{\gamma\left(\tau_{p}\right)-\gamma_{0}}
$$

\subsection{Crack Observation}

The entire taper section of the specimen was observed after each unloading using an optical microscope (BH2-UMA; Olympus Corp., Tokyo, Japan). We observed both planes separately with different specimens because of the taper geometry, which is not proper for optical microscope observations. The magnification was set at 100 times, which has no 
more than $1 \mu \mathrm{m}$ resolution, for finding cracks and measuring their length, number and angle following the methods used for earlier reports: the crack length was measured from the major axis of the eclipse surrounding a crack, using an open sauce software Fiji, while the crack angle was measured from the inclination to the loading direction, which was defined as the crack angle $[9,10]$. In addition, 25-times magnified images were taken to make crack propagation process map images using an open source image analysis tool Open CV of Python for image synthesis and an open source image editor, GIMP 2.10.12 for drawing cracks on the synthetic image.

\section{Results and Discussion}

\subsection{Stress-Strain Relation}

Figure 4a shows the typical stress-strain relation of the shear loading test of the inplane. The shear strength was $57(+3-2) \mathrm{MPa}$, where + or - represents the difference from the average value. The fracture strain was $0.34(+0.08-0.05 \%)$. The graph presents the nonlinear stress-strain relation. Figure $3 \mathrm{~b}$ shows the typical stress-strain relation of the shear loading test of the through-thickness plane. The shear strength was $32( \pm 2) \mathrm{MPa}$, where + or - represents the difference from the average value. The fracture strain was $0.73(+0.68-0.33 \%)$. The graph also presents the nonlinear stress-strain relation.

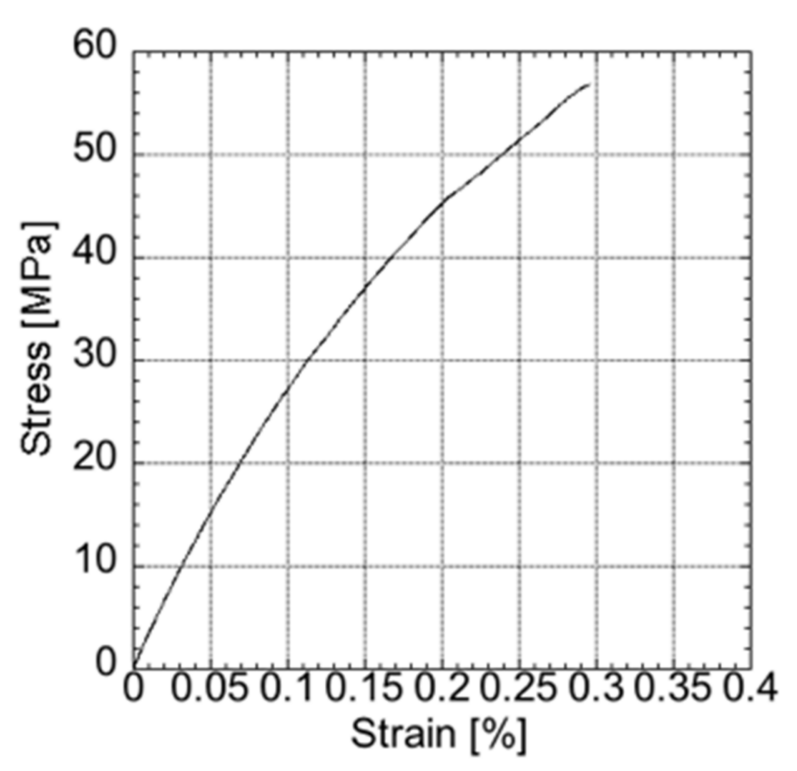

(a)

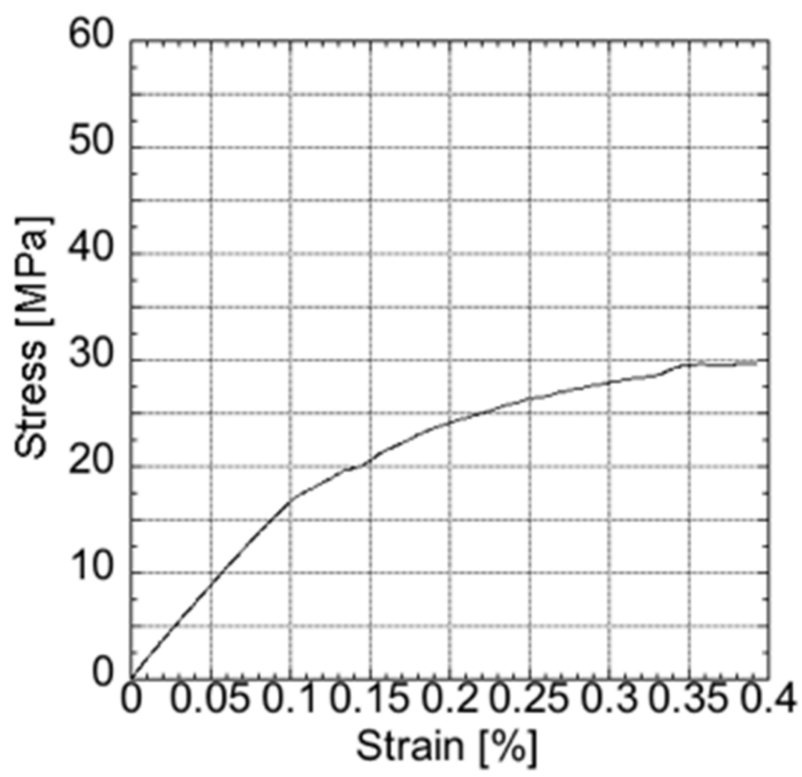

(b)

Figure 4. Stress-strain relations of shear loading test: (a) in-plane specimen and (b) through-thickness plane specimen.

Figure 5a shows the example of each direction of strain under the shear of the in-plane. The line depicted in the center curve shows the summation of strains for each direction. The strain of tensile direction shows an almost identical value to that of compression below $42 \mathrm{MPa}$ (or $0.08 \%$ strain). Above that value, however, it increases more than that of compression, which can also be found from the center line. Figure $5 \mathrm{~b}$ presents an example of each direction of strains of the through-thickness plane. The strain of the tensile direction was greater than that of compressive direction.

Figure 6 presents a comparison of the average shear, compressive and tensile strain of the in-plane specimen. The compression and tension plots were referred from earlier works $[9,10]$. Decomposed strains of shear are close to the value of each case of monotonic compression and tension. This finding suggests that the mechanism of the nonlinear stress-strain relation of monotonic compression and tension resembles that of shear. 


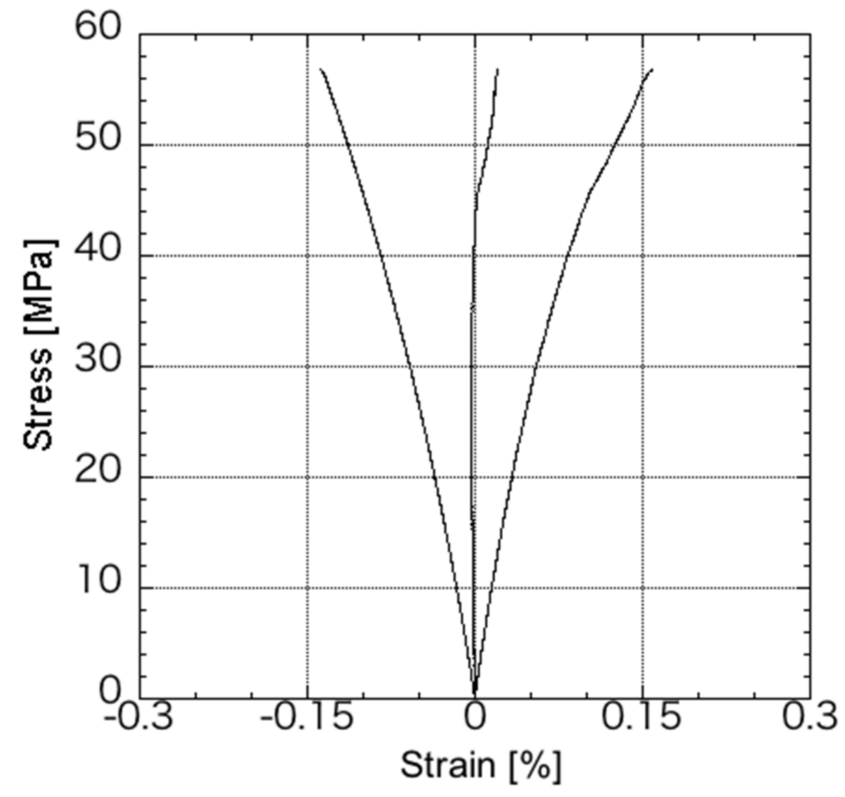

(a)

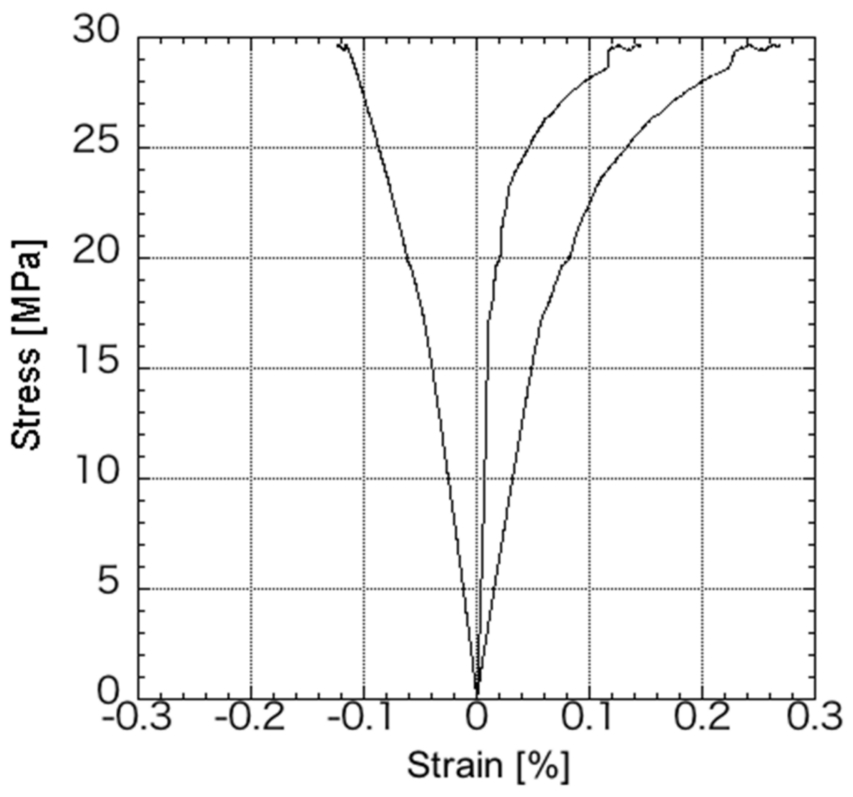

(b)

Figure 5. Comparison of tensile and compressive direction strain during shear loading test. The curves of the center present the sum of both strains: (a) in-plane specimen and (b) through-thickness plane specimen.

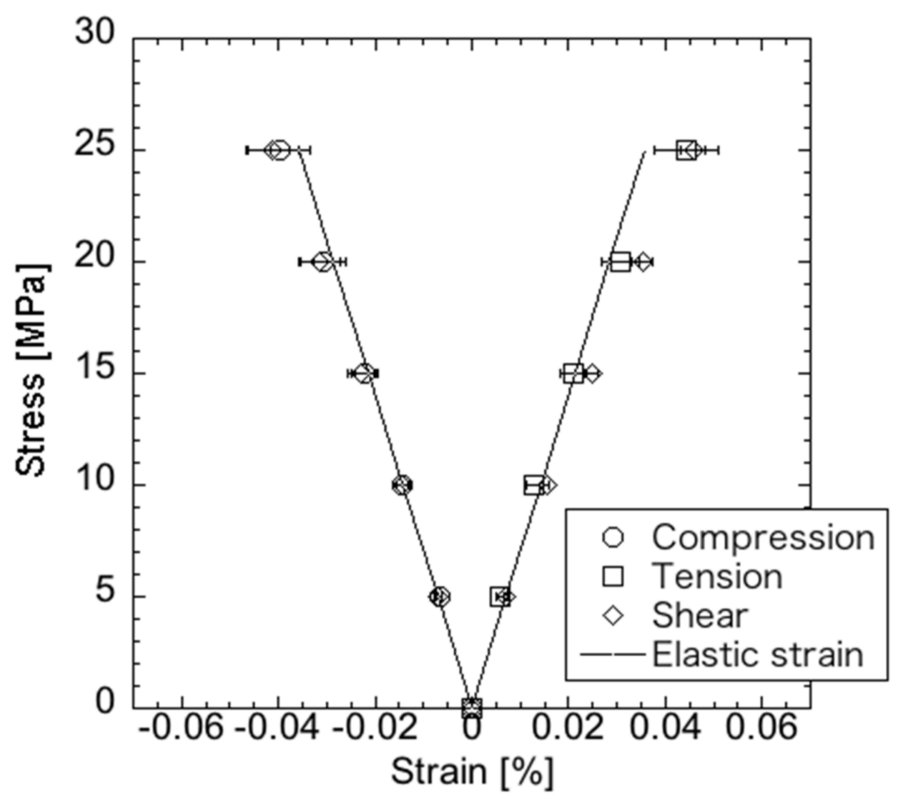

Figure 6. Comparison of average strain of in-plane between compressive, tensile and shear loading test (circle, compression; square, tension; rhombus, shear; solid line, elastic strain of each direction of decomposed shear loading). Data of compression and tension were quoted from an earlier report $[9,10]$.

Figure 7a portrays the typical stress-strain relation of the loading-unloading tests of the in-plane specimen. During loading, the strain increases nonlinearly. During unloading, it decreases linearly. Figure $7 \mathrm{~b}$ shows the typical stress-strain relation of the loadingunloading tests of the through-plane. During loading, the strain increases nonlinearly. Above the $25 \mathrm{MPa}$ peak stress, it shows particularly nonlinear strain. Under unloading, it decreases linearly as well as the case of in-plane specimen. 


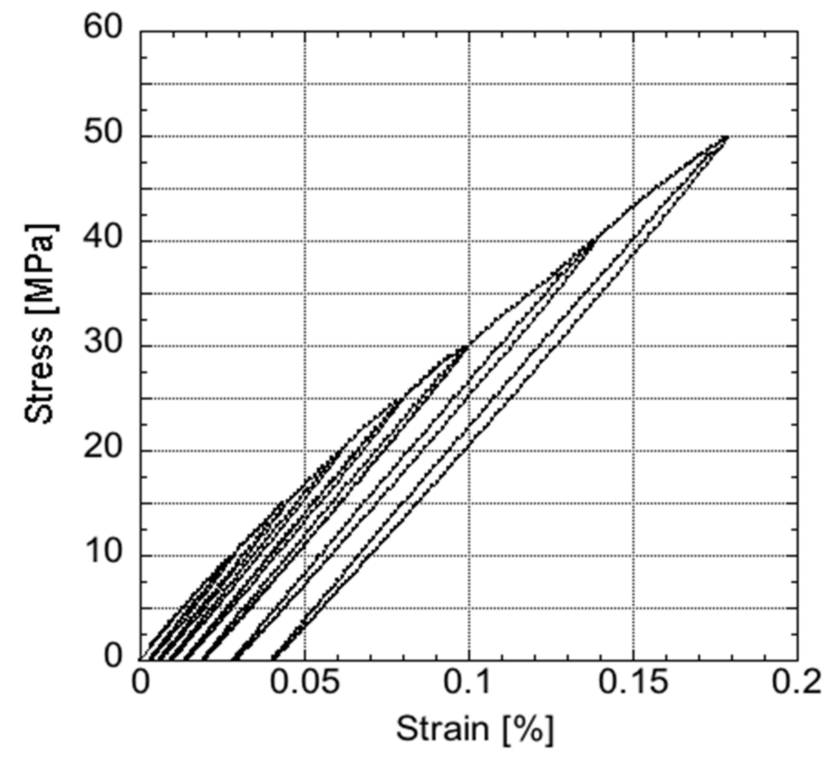

(a)

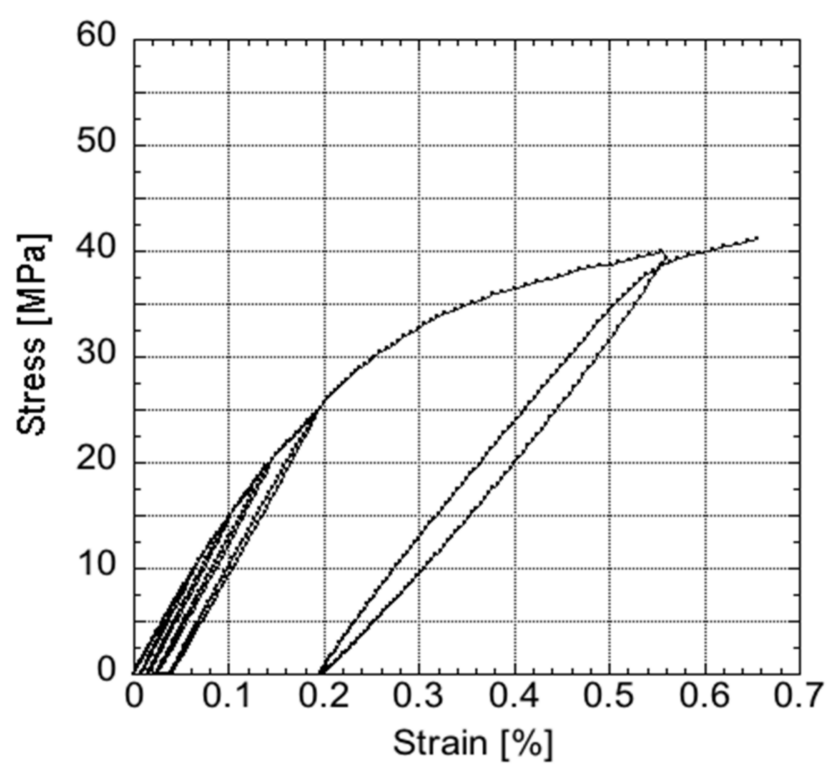

(b)

Figure 7. Optical microscope surface image of macro feature of specimen: (a) in-plane (A, fiber bundle; B, Si phase; C, SiC phase; D, pore; E, process-crack); (b) through-thickness plane (characters in the figure are the same as those for the in-plane surface image.).

Figure 8a presents a comparison of unloading shear modulus $G_{u}$ of the in-plane and through-thickness plane. The unloading modulus of in-plane shows $40 \mathrm{GPa}$ constantly before fracture, whereas that of through-thickness plane shows $18 \mathrm{GPa}$ constantly as well. Therefore, we define each composite shear modulus $G_{c}$ as $40 \mathrm{GPa}$ for in-plane and $18 \mathrm{GPa}$ for the through-thickness plane.

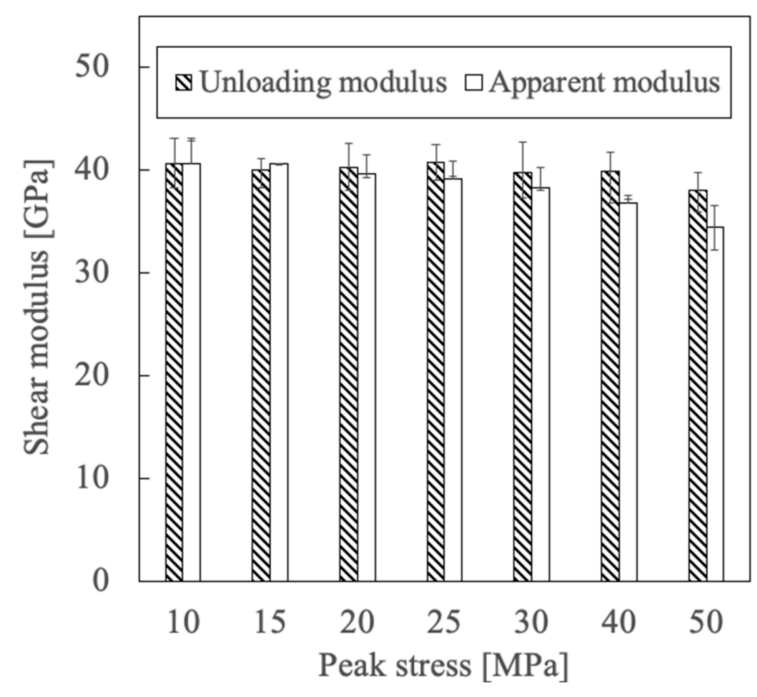

(a)

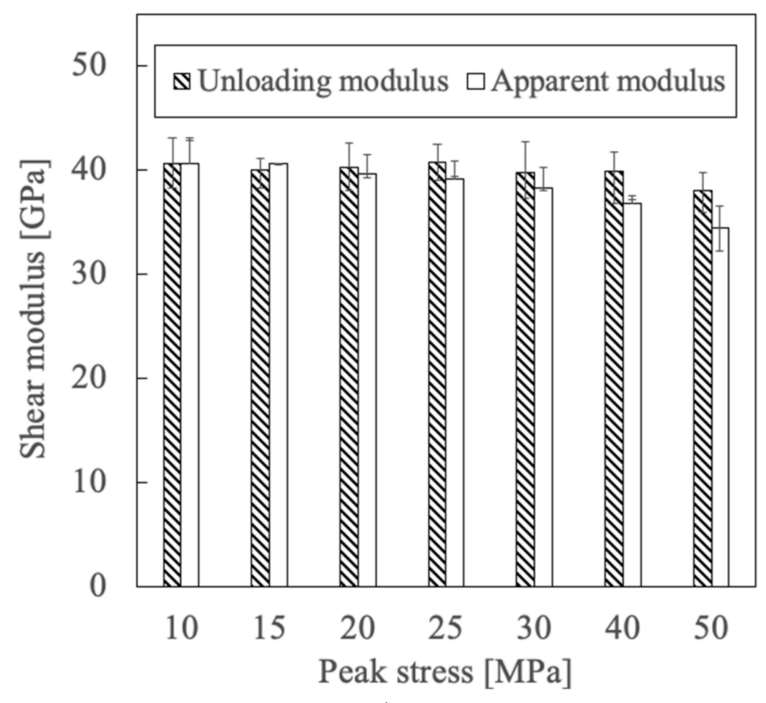

(b)

Figure 8. Relations between modulus and peak stress. The oblique pattern presents unloading modulus. The white pattern presents apparent modulus: (a) in-plane specimen and (b) through-thickness plane specimen.

Figure $8 \mathrm{~b}$ presents a comparison of apparent modulus $G^{*}$ of in-plane and the throughthickness plane. The apparent modulus of in-plane decreases concomitantly with increased peak stress, whereas that of the through-thickness plane also decreases concomitantly. This reason seems to derive from the crack propagation of transverse fibers from reference to reports of tension and compression $[9,10]$. 
Figure 9a shows the variation of peak strain and permanent strain in-plane with increased peak stress. The peak strain nonlinearly increases concomitantly with increased peak stress and permanent strain. This tendency is similar to that reported in the earlier works, suggesting a crack opening in loading $[9,10]$. The value of permanent strain ranges from one-fifth or larger to one-third that of the peak strain at each peak stress. This behavior also resembles that under tension. Figure $9 \mathrm{~b}$ presents variation of peak strain and permanent strain of the through-thickness plane. The relation between peak strain and peak stress shows a nonlinear increase. The permanent strain also increased nonlinearly, proposing the crack opening. The value of permanent strain was one-fifth that of the peak strain at each peak stress, as in the in-plane case.

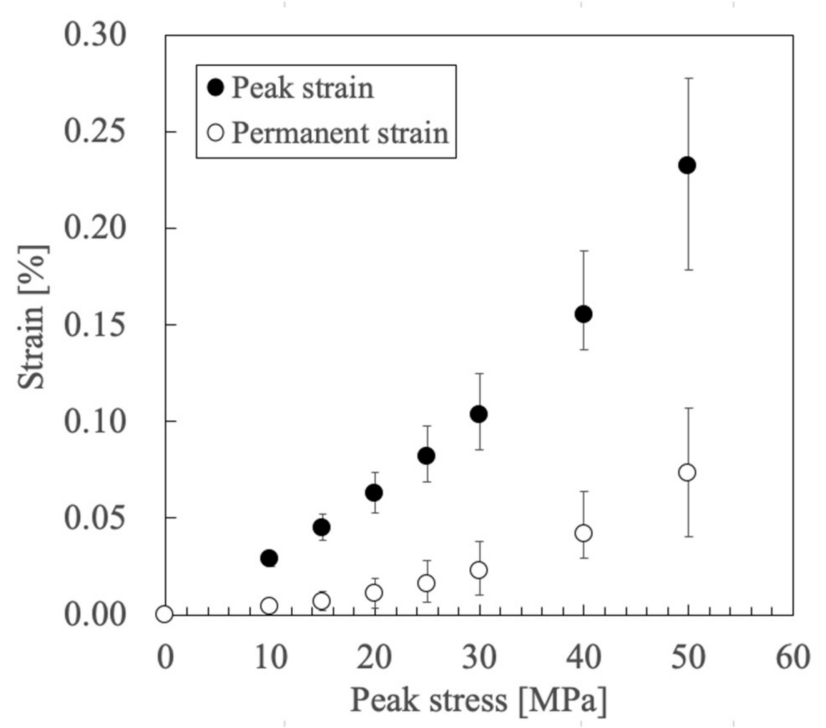

(a)

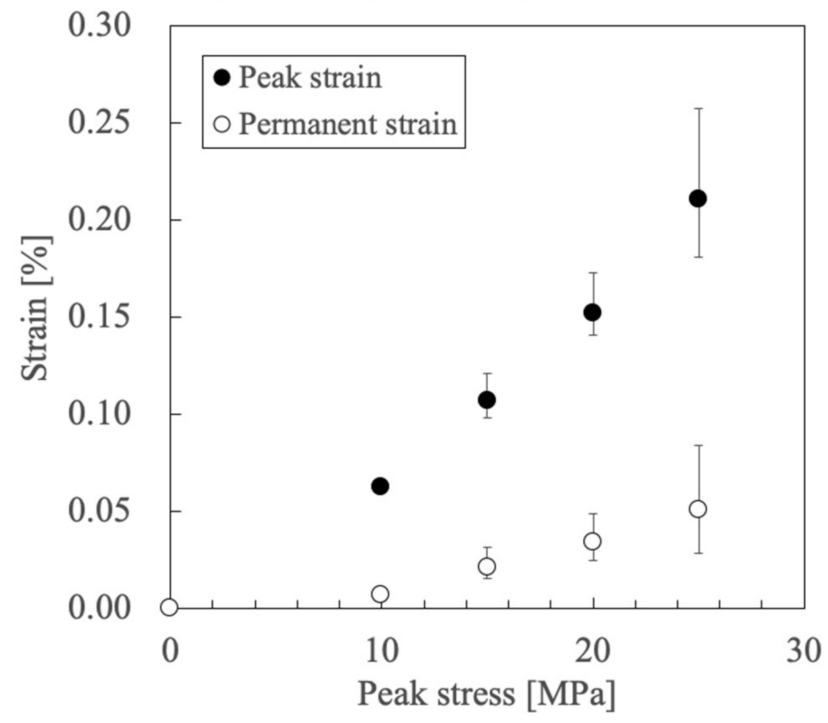

(b)

Figure 9. Comparison of peak strain and permanent strain. The solid plot presents peak strain. The hollow plot presents permanent strain: (a) in-plane specimen and (b) through-thickness specimen.

\subsection{Crack Propagation Process}

Figure 10 shows typically obtained magnified images of crack propagations. Figure 10a portrays a propagated crack in the transverse fiber bundle of the through-thickness plane. Cracks intruded in the boundary of transverse fibers without fiber fracture, as in the case of compression and tension $[9,10]$. Figure 10b shows crack propagation in the Si phase. The crack extended until it reached the interface to the fiber bundles. Figure 11 shows a typical crack propagation process. Before loading, process cracks exist, as indicated by white arrows (Figure 11a). After loading, cracks extended from process cracks, connecting others. This propagation behavior was the same as that observed in the case of compression and tension $[9,10]$.

Figure 12 shows mapping images of crack propagation of each plane. In the case of the in-plane specimen, crack propagation was not confirmed below $40 \mathrm{MPa}$ peak stress (Figure 12a). Above that value, cracks grew up with increased peak stress. After fracture, cracks propagated perpendicularly to the tensile direction. Comparing the crack locations found before and after fracture, many of them correspond well. As shown in Figure 11, cracks grew up, connecting others, and thereby overall fracture seems to occur as well. In the case of the through-thickness specimen, crack propagation was not confirmed below $20 \mathrm{MPa}$ peak stress (Figure 12b). Above that value, cracks extended with increased peak stress. After fracture, cracks propagated perpendicularly to the tensile direction from the notch. Comparing the crack locations found before and after fracture, some of them 
correspond well, which also suggests that fracturing was caused by linkage of propagating cracks.

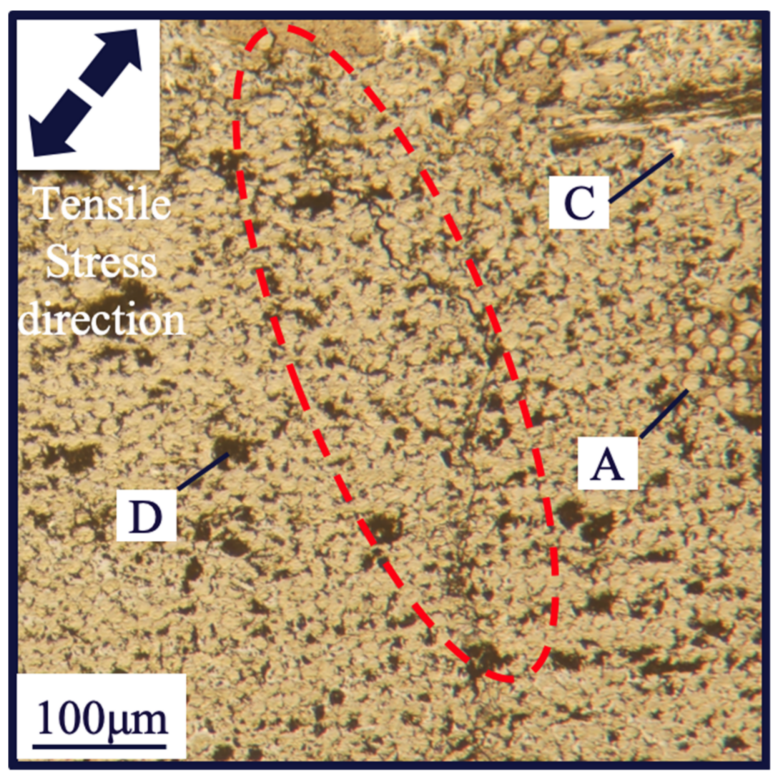

(a)

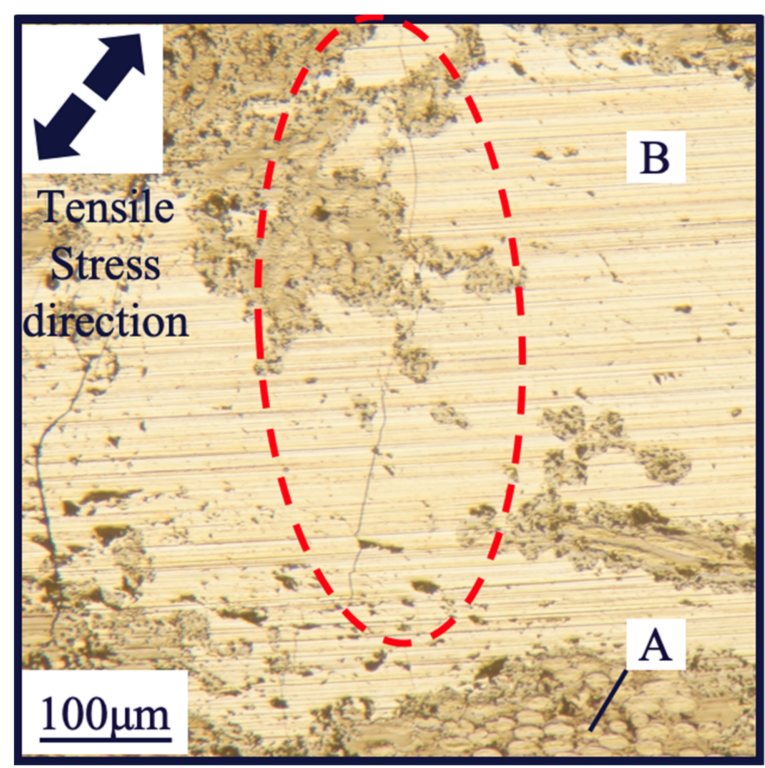

(b)

Figure 10. Crack propagation regions: A, single fiber; B, Si phase; C, SiC phase; D, pore. Images show post-unloading. The loading directions of the decomposed tensile direction of shear stress are indicated by arrows in the images. The region surrounded by a circle shows a part of crack propagation: (a) transverse fiber bundle (through-thickness plane specimen) and (b) Si phase (through-thickness plane specimen).

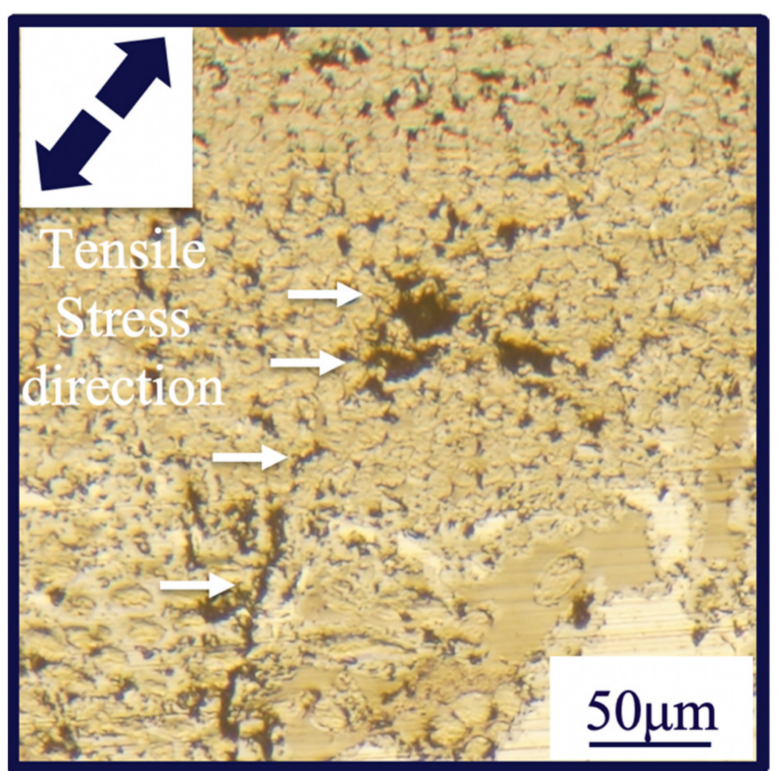

(a)

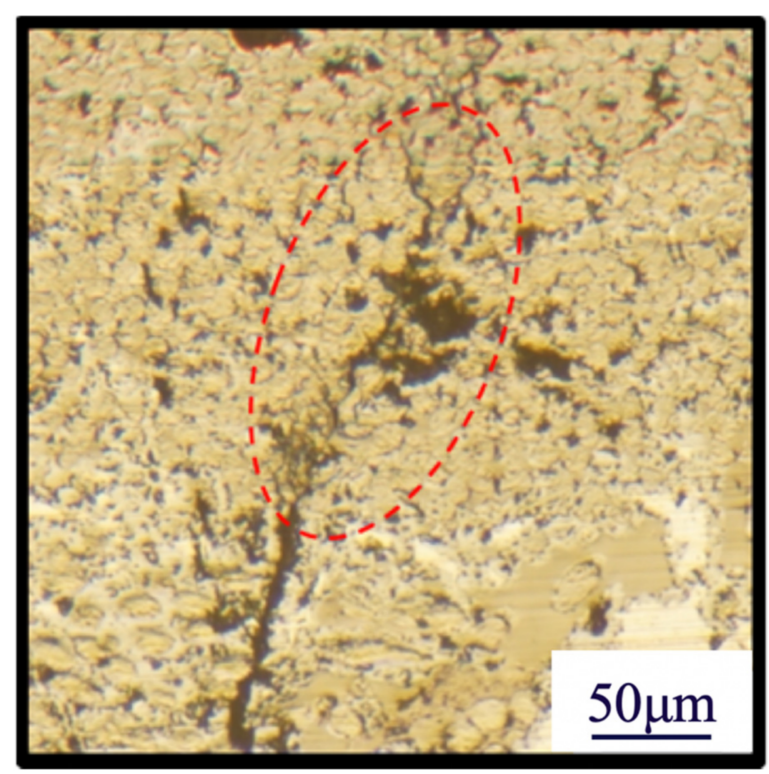

(b)

Figure 11. Typical crack propagation process: white arrows indicate the process crack location. The oval shows the area of crack propagation. The loading direction of the decomposed tensile direction of shear stress, as indicated with solid arrows. (a) Before loading (through-thickness plane specimen). The arrows indicate the process crack location. (b) After $25 \mathrm{MPa}$ unloading. Process cracks extended and connected with others. 

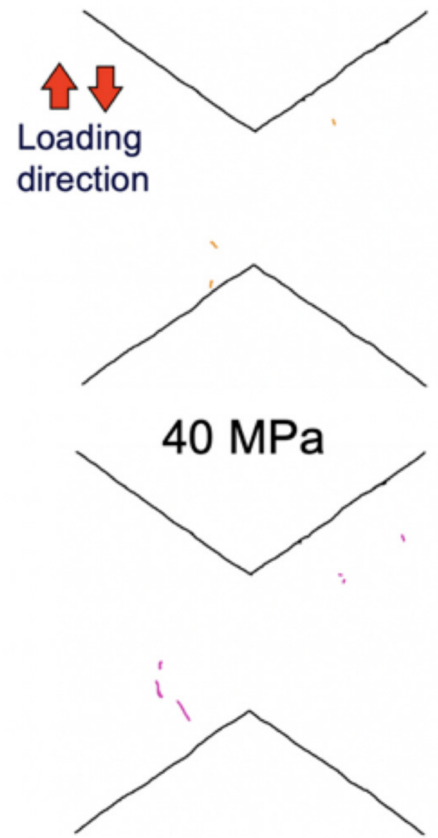

$60 \mathrm{MPa}$
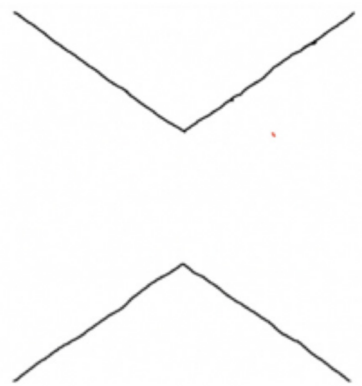

$50 \mathrm{MPa}$

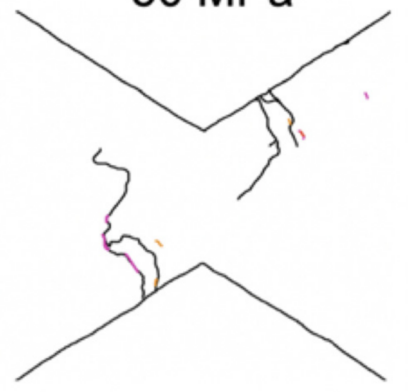

All $5 \mathrm{~mm}$
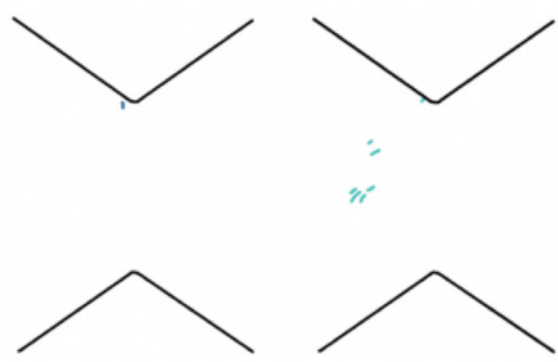

$20 \mathrm{MPa}$

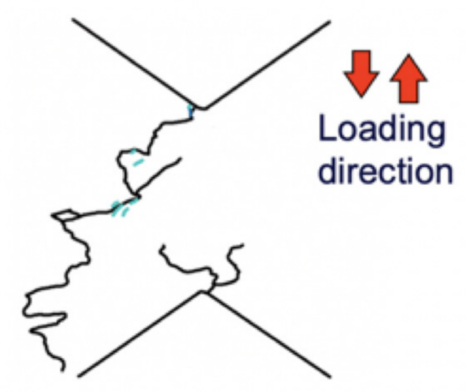

All

$5 \mathrm{~mm}$

(a)

Figure 12. Crack propagation map. The crack propagation at each peak stress is depicted in the images. The shear loading direction has accordance with the vertical direction in the images: (a) in-plane specimen and (b) through-thickness plane specimen.

\subsection{Damage Characteristics}

Figure 13a presents a comparison of the total newly propagated crack length of each peak stress related to the in-plane specimen (oblique line pattern, fiber bundle; white pattern, Si phase). The plots of more than $50 \mathrm{MPa}$ peak stress have no error bar because the other sample fractured before that value. The graph shows that few cracks propagated below 30 MPa peak stress. Above that value, the crack length increased concomitantly with increased peak stress. The fiber bundle crack length is much greater than that of $\mathrm{Si}$ phase. This finding suggests that cracks propagated mainly in the fiber bundle region. Figure $13 \mathrm{~b}$ presents a comparison of the total newly propagated crack length of each peak stress related to the through-thickness plane. Data of more than $30 \mathrm{MPa}$ peak stress have no error bar because the other sample fractured before that value. The graph reflects that few cracks propagated below 20 MPa peak stress. Above that value, the crack length increased concomitantly with increased peak stress. The crack length of fiber bundles is much greater than that of Si phase, which also suggests that cracks propagated mainly in the fiber bundle region.

Figure 14a presents a comparison of maximum crack lengths at the respective peak stresses related to the in-plane specimen. Data of more than $50 \mathrm{MPa}$ peak stress have no error bar because the other sample fractured before that value. The maximum crack lengthdid not change until $30 \mathrm{MPa}$ peak stress. However, at $40 \mathrm{MPa}$ peak stress, the maximum crack length of a sample reached $6 \mathrm{~mm}$, whereas that of the other one shows a close value $(5 \mathrm{~mm})$ at $60 \mathrm{MPa}$. Considering that these stresses are the closest stress to the fracture, the damage-tolerant crack length in-plane is apparently more than $5 \mathrm{~mm}$. Figure $14 \mathrm{~b}$ presents a comparison of maximum crack length of each peak stress related to the through-thickness specimen. Data of more than $30 \mathrm{MPa}$ peak stress have no error bar because the other sample fractured before that value. The maximum crack length did not 
change until $20 \mathrm{MPa}$ peak stress. Above that stress, the length increased concomitantly with increased peak stress. Furthermore, the maximum crack length of each sample at maximum shows more than $3.0 \mathrm{~mm}$, which suggests that the damage-tolerant crack length is greater than that value.

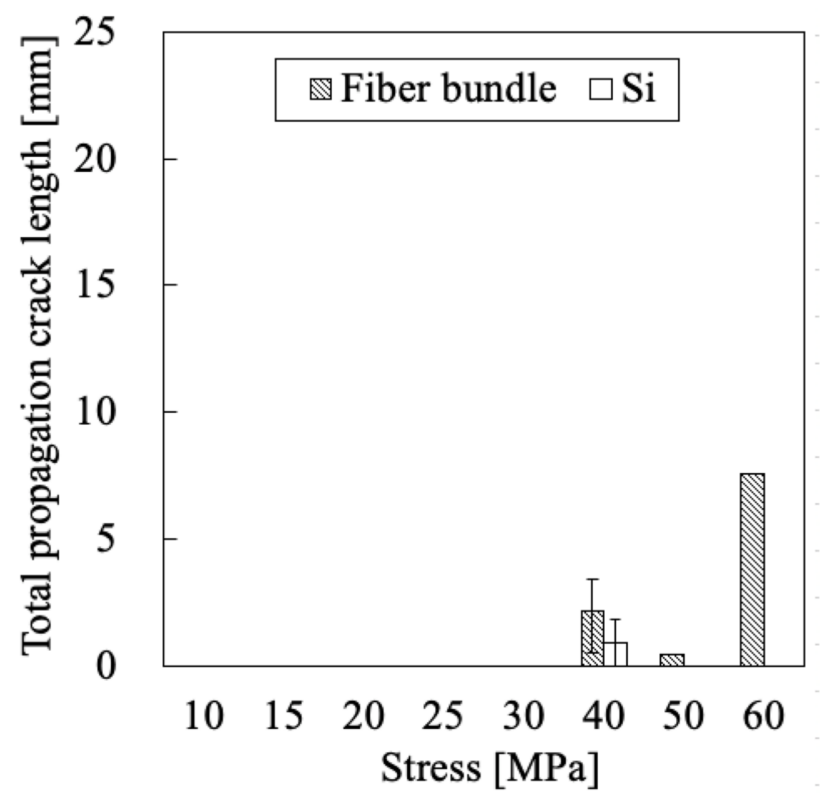

(a)

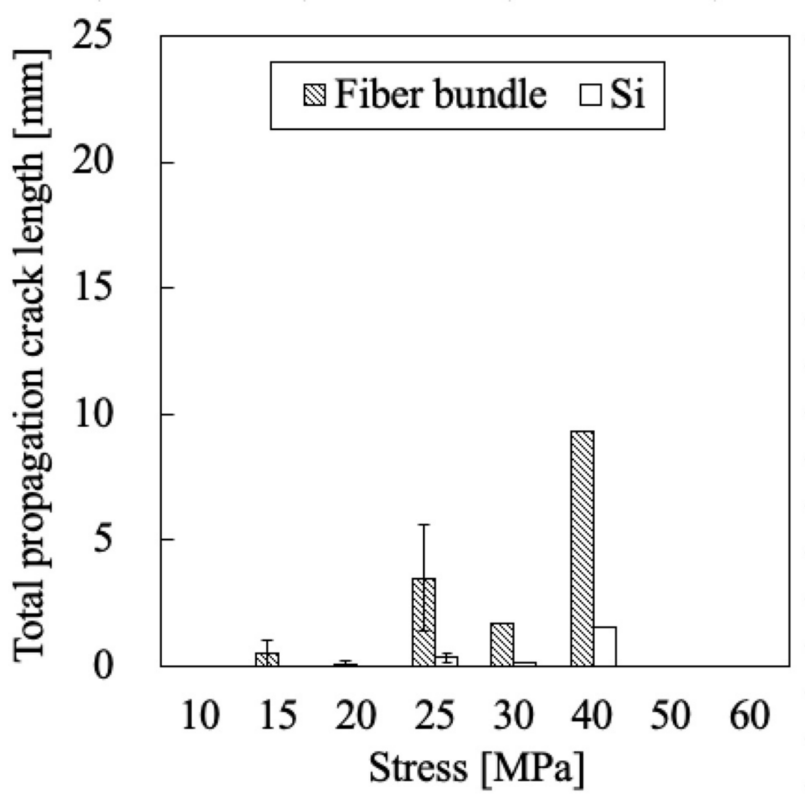

(b)

Figure 13. Relation between total propagation crack length and peak stress. The oblique pattern represents the fiber bundle. The white pattern represents Si phase: (a) in-plane and (b) through-thickness plane. Some data have no error bar because other samples fractured earlier.

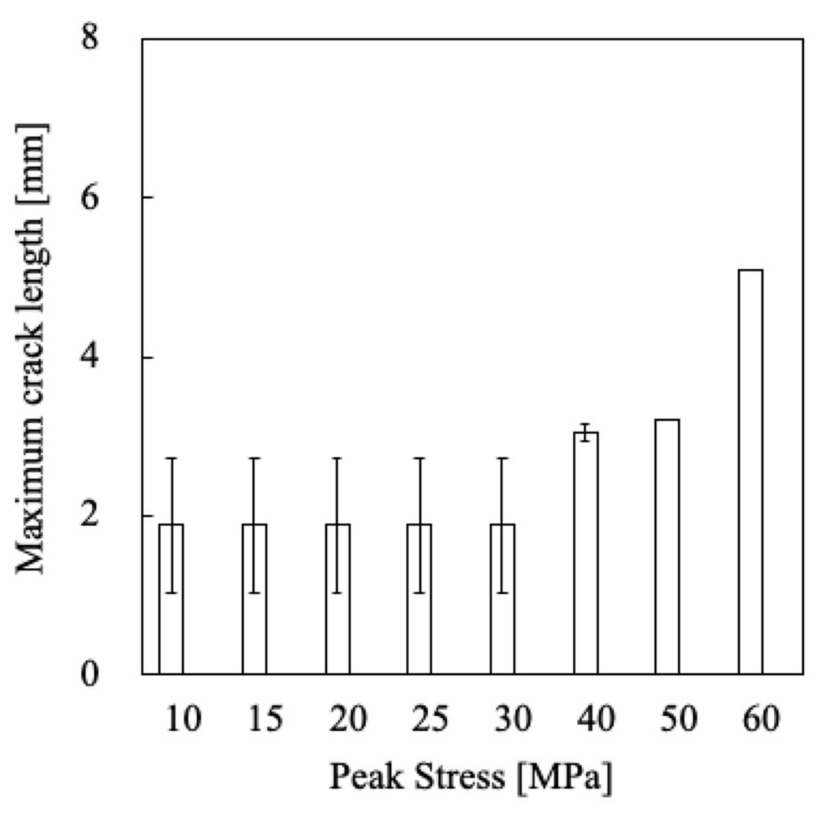

(a)

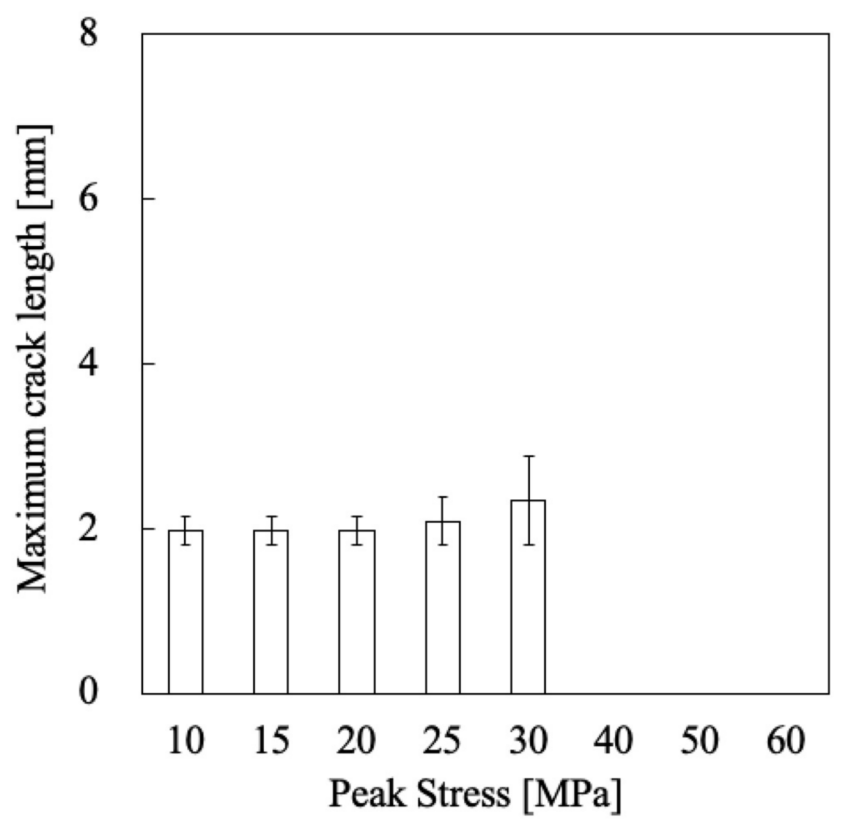

(b)

Figure 14. Relation between maximum crack length and peak stress (a) in-plane and (b) through-thickness plane. Some data have no error bar because other samples fractured earlier.

Figure 15a shows the average crack length distribution of each angle for in-plane. The horizontal axis shows the inclination to the decomposed tensile direction stress from the 
shear stress. The graph shows that most cracks propagated perpendicularly to the tensile direction of shear stress. Figure 15b shows the average crack length distribution of each angle regarding the through-thickness plane. The graph shows that most of the cracks propagated perpendicularly to the tensile direction of the shear stress, as in the case of the in-plane specimen.

Earlier studies investigated damage characteristics (average crack length, number and angle) of the through-thickness plane for estimation of stress-strain relations, because most cracks propagated compared to those in-plane $[8,9]$. This crack propagation behavior was also confirmed by this study. Therefore, we followed this method and investigated damage characteristics of the through-thickness "plane" of the through-thickness "speci-men", whereas that of in-plane specimens could not be observed with an optical microscope because of their notch geometry.

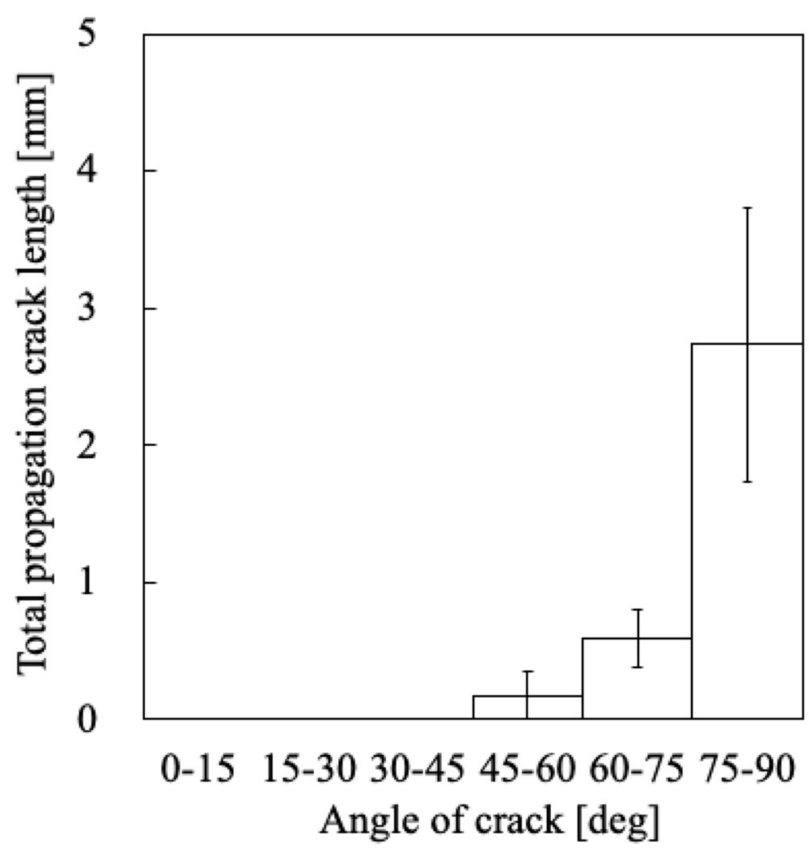

(a)

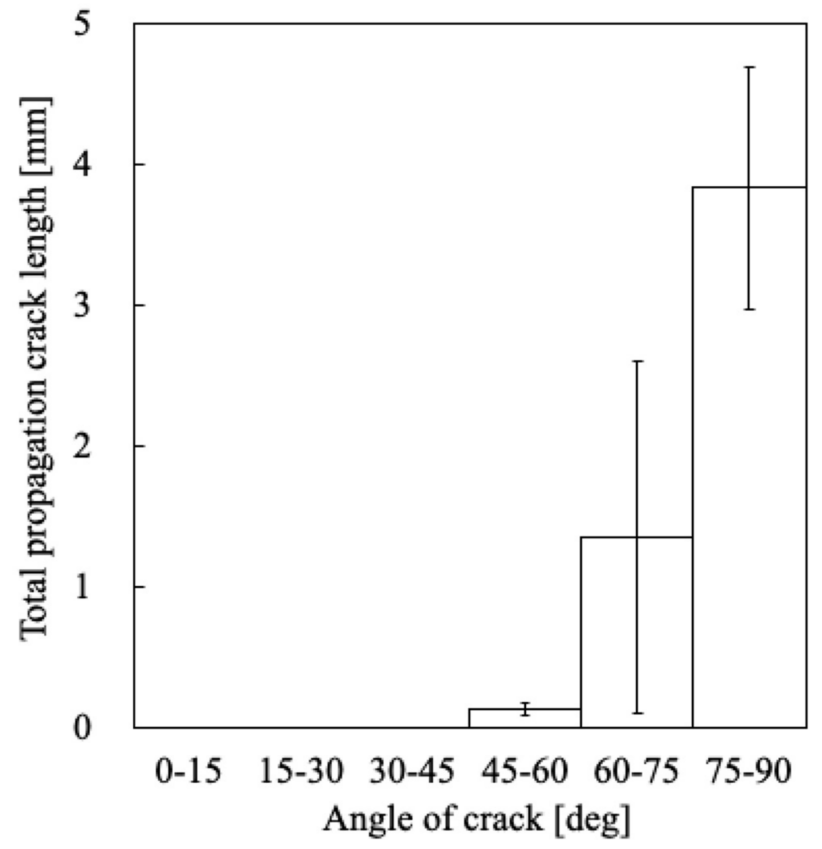

(b)

Figure 15. Relation between crack angle and total propagated crack length. The angle shows inclination to the tensile axis: (a) in-plane specimen and the (b) through-thickness plane specimen.

Table 1 presents damage characteristics of the initial process cracks and propagated cracks related to the through-thickness plane. The values described in $0 \mathrm{MPa}$ peak stress denote the damage characteristics of process cracks, whereas those described in more than $10 \mathrm{MPa}$ peak stress only denote characteristics of the propagated process cracks with increased peak stress. We calculated the crack density as

$$
\omega=N c^{2} / A
$$

where $N$ represents the number of cracks, $c$ denotes the crack length and $A$ stands for the observation area. We defined the observation area to cover the entire notch area $\left(58 \mathrm{~mm}^{2}\right)$, considering the size of strain gages and crack propagation area after fracture. The table shows that the number of $0 \mathrm{MPa}$ is much larger than that of more than $10 \mathrm{MPa}$ peak stress. This behavior is similar to that of compression and tension $[9,10]$. The average crack density of $0 \mathrm{MPa}$ is also higher than that of more than $10 \mathrm{MPa}$ peak stress. However, after $20 \mathrm{MPa}$ peak stress, its crack density is equivalent to that of $0 \mathrm{MPa}$, which results from the increase in the average crack length. 
Table 1. Damage characteristics of through-thickness plane specimen: $0 \mathrm{MPa}$ shows those of process cracks; over $10 \mathrm{MPa}$ shows data of propagated cracks.

\begin{tabular}{|c|c|c|c|c|c|}
\hline & \multicolumn{5}{|c|}{ Peak Stress [MPa] } \\
\hline & 0 & 10 & 15 & 20 & 25 \\
\hline Average length & 186 & 317 & 317 & 327 & 886 \\
\hline$c[\mu \mathrm{m}]$ & \pm 6 & \pm 34 & \pm 34 & \pm 43 & \pm 185 \\
\hline Number & 128 & \multirow{2}{*}{\multicolumn{4}{|c|}{$\begin{array}{c}8 \\
\pm 3\end{array}$}} \\
\hline$N[-]$ & \pm 1 & & & & \\
\hline Average angle & 40 & \multicolumn{4}{|c|}{$\begin{array}{r}76 \\
+5\end{array}$} \\
\hline$\gamma[\mathrm{deg}]$ & \pm 2 & & & & \\
\hline
\end{tabular}

\subsection{Estimation of the Stress-Strain relation of the Through-Thickness Plane}

This section presents discussion of reasons for the nonlinear stress-strain relation. To elucidate this point, we estimated the stress-strain relation of the through-thickness plane. Earlier reports related to the compressive and tensile cumulative damage mechanism described estimation of the stress-strain relation by referring the damage characteristics of the through-thickness plane at which the most crack propagation was confirmed, which is similar to these study results $[9,10]$. However, the present study failed to measure characteristics of both planes with the same specimen because of taper geometry, which disturbs optical microscope observations. Therefore, we strove to estimate the stress-strain relation of the through-thickness specimen.

Considering Equation (1), which calculates the shear strain from the summation of absolute strain values of the tensile and compressive directions, we separately estimate the strains of each direction. In addition, the strain is calculable by adding the elastic strain, inelastic strain and permanent strain.

$$
\gamma_{p}=\frac{\tau_{p}}{G_{c 13}}+\int_{0}^{\tau_{p}} d \varepsilon^{i,+}+\int_{0}^{\tau_{p}} \varepsilon^{i,-}+\gamma_{0}
$$

Therein, $G_{c 13}$ denotes the shear modulus of the through-thickness specimen, $\tau_{p}$ denotes the applied shear stress, $\varepsilon^{i,+}$ denotes the inelastic strain of the tensile direction and $\varepsilon^{i,-}$ denotes the inelastic strain of the compressive direction.

Inelastic strain of the tensile direction $\varepsilon^{i,+}$ is calculable by referring the previously proposed equations assuming two-dimensional deflected ellipsoid cracks in the isotropic body for simplification [10].

$$
\begin{gathered}
d \varepsilon^{i,+}=d \varepsilon+d \varepsilon \\
d \varepsilon=\frac{2 N c \cos ^{2}\left(\frac{\pi}{2}-\psi\right) \cdot d \bar{v}+N c \sin (\pi-2 \psi) \cdot d \bar{u}}{A} \\
d \varepsilon=\frac{N c \sin (\pi-2 \psi) \cdot d \bar{u}+2 N c \cos ^{2}\left(\frac{\pi}{2}-\psi\right) \cdot d \bar{v}}{A}
\end{gathered}
$$

In those equations, $N$ stands for the crack number, $c$ represents the average crack length and $\psi$ denotes inclination to the tensile direction stress. These damage characteristics were substituted separately from values of not propagated process cracks and propagated cracks, as shown in Table 1 . Then, each inelastic strain was summed up. In the equation, $A$ denotes the observation area. Moreover, $\bar{u}$ and $\bar{v}$, respectively, represent the average crack opening displacement of each direction obtained using Equations ((9)-(21)), considering the $r-\theta$ coordinate systems of elliptic crack geometry.

$$
\bar{u}=\frac{2}{c} \int_{\frac{c}{2}}^{0} u(x) d x
$$




$$
\begin{gathered}
\bar{v}=\frac{2}{c} \int_{\frac{c}{2}}^{0} v(x) d x \\
\theta=\pi-\cos ^{-1} \frac{2 x-c}{2 r} \quad(0<x<c) \\
r=\sqrt{\left\{1-\left(\frac{b}{c}\right)^{2}\right\} x^{2}-c x+\frac{1}{4} c^{2}+\frac{1}{4} b^{2}} \\
\bar{u}=\frac{\left(1+v_{13}\right) K \sqrt{2 r}}{E c_{c 13}} \cos \frac{\theta}{2}\left\{1-2 v+\sin ^{2} \frac{\theta}{2}\right\} \\
\bar{v}=\frac{\left(1+v_{13}\right) K \sqrt{2 r}}{E \prime_{c 13}} \sin \frac{\theta}{2}\left\{2(1-v)-\cos ^{2} \frac{\theta}{2}\right\} \\
\bar{u}=\frac{\left(1+v_{13}\right) K \sqrt{2 r}}{E \prime_{c 13}} \sin \frac{\theta}{2}\left\{2(1-v)+\cos ^{2} \frac{\theta}{2}\right\} \\
\bar{v}=\frac{\left(1+v_{13}\right) K \sqrt{2 r}}{E c_{c 13}} \cos \frac{\theta}{2}\left\{1-2 v-\sin ^{2} \frac{\theta}{2}\right\} \\
K=\sigma^{\prime} \sqrt{c / 2} \\
K=\tau^{\prime} \sqrt{c / 2} \\
\sigma^{\prime}=\sigma \cos ^{2}\left(\frac{\pi}{2}-\psi\right) \\
\tau^{\prime}=\frac{1}{2} \sigma \sin (\pi-2 \psi) \\
\sigma=\tau_{p}
\end{gathered}
$$

In those equations, $b$ denotes the minor axis length, which is equal to the crack width $(<10 \mu \mathrm{m})$; moreover, $v_{13}$ denotes Poisson's ratio of the through-thickness plane. We substituted 0.3 following the method used for an earlier study [8]. $E \prime_{c 13}$ denotes Young's modulus of tensile direction considering Hooke's law regarding $45^{\circ}$ tilted direction, which differs from the case of an earlier report. The value of $E I_{c 13}$ is calculable as shown below.

$$
\begin{aligned}
E_{c 13}^{\prime} & =1 / \bar{S}_{11} \\
\bar{S}_{11}=S_{11} l^{4}+\left(2 S_{13}+S_{55}\right) l^{2} m^{2} & +S_{33} m^{4} \quad(l=\cos \theta, m=\sin \theta) \\
S_{11} & =1 / E_{c 11} \\
S_{13} & =-v_{13} / E_{c 11} \\
S_{33} & =1 / E_{c 33} \\
S_{55} & =1 / G_{c 13}
\end{aligned}
$$

Therein, Young's modulus of each direction was referred from an earlier report ( $E_{c 11}$, $\left.70 \mathrm{GPa} ; E_{c 33}, 28 \mathrm{GPa}\right)[9]$.

Inelastic strain of the compressive direction $\varepsilon^{i,-}$ is calculable by considering the mode II crack opening, because $K$ is negative in compression, and by using Equation (8), Equations ((9)-(12)) and Equations ((15)-(16)). In addition, many studies have indicated the closed crack inside slipping $[9,22,23]$. Therefore, we substituted the following equation for the calculation of $K$ instead of Equation (20), as

$$
\tau^{\prime \prime}=\frac{1}{2} \sigma \sin (\pi-2 \psi)-\mu \sigma \cos ^{2}\left(\frac{\pi}{2}-\psi\right),
$$


where $\mu$ is the frictional coefficient of crack interfaces. Considering that most cracks propagated in the transverse carbon fiber bundles, and referring to an earlier report, we substituted 0.2 into Equation (25).

Permanent strain is calculable from the following equation, considering the linear relation in unloading, as shown in Figure 5, and subtracting the elastic strain from the peak strain.

$$
\gamma_{0}=\gamma_{p}-\frac{\tau_{p}}{G_{c 13}}
$$

Figure 16 presents a comparison between the estimated stress-strain relations and results (circle, results; square, estimations). Estimations show a nonlinear stress-strain relation. In addition, the plots correspond to results well. Consequently, the proposed shear strain estimation method is valid.

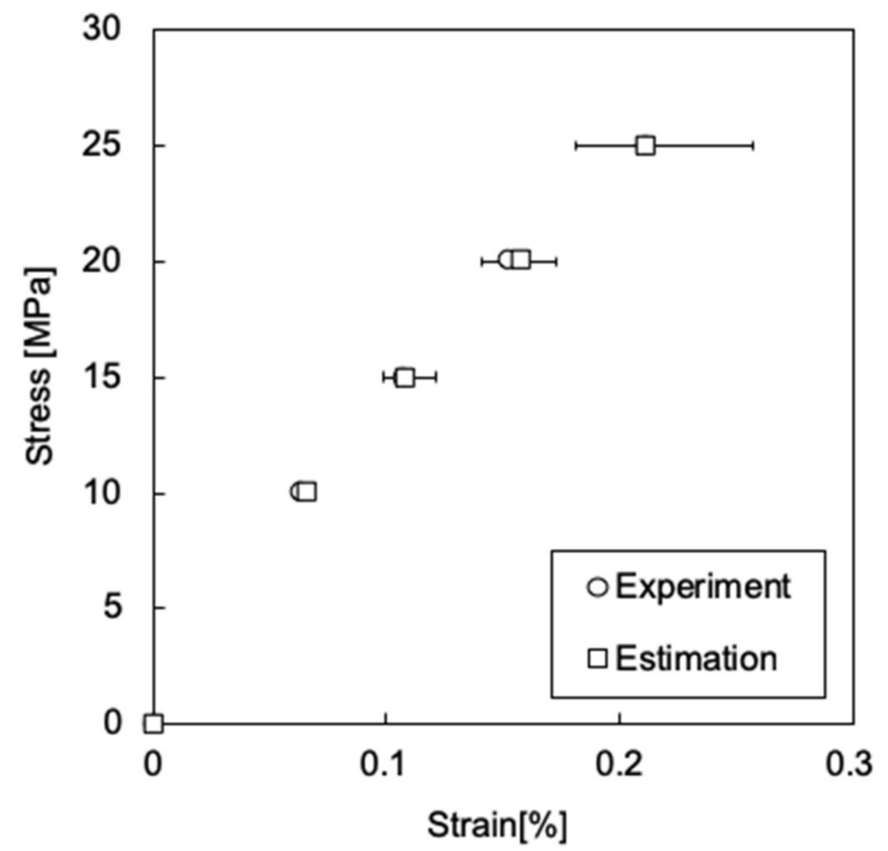

Figure 16. Estimation of stress-strain relation: circles represent results; squares represent estimations.

Figure 17 presents a comparison between the estimated permanent strain and results (circle, results; square, estimations). The estimation shows a nonlinear stress-strain relation along with results. Moreover, the plots correspond to the results well. Consequently, results verify that the proposed shear strain estimation method is valid. Shear strain can be estimated from the summation of tensile and compressive strain. Furthermore, inelastic strain can be caused by the mixed mode I and II crack opening in the transverse fiber bundles.

\subsection{Reason for Larger Inelastic Strain of Tensile Direction}

We next discuss the reason for the larger inelastic strain of the tensile direction compared to that of the compressive direction, as shown in Figure $5 b$. One possible reason is the almost perpendicular crack propagation angle, because $K$ is close to zero. Another possible reason is apparently the friction of closed cracks inside surfaces. In tension, cracks open in loading, which causes no friction. However, in compression, cracks close and slip inside surfaces. Yet another possible reason is the difference of crack opening modes. As discussed in Section 3.4, inelastic strain of tensile direction results from the mixed mode I and II crack opening, whereas that of the compressive direction only results from the mode II crack opening. 


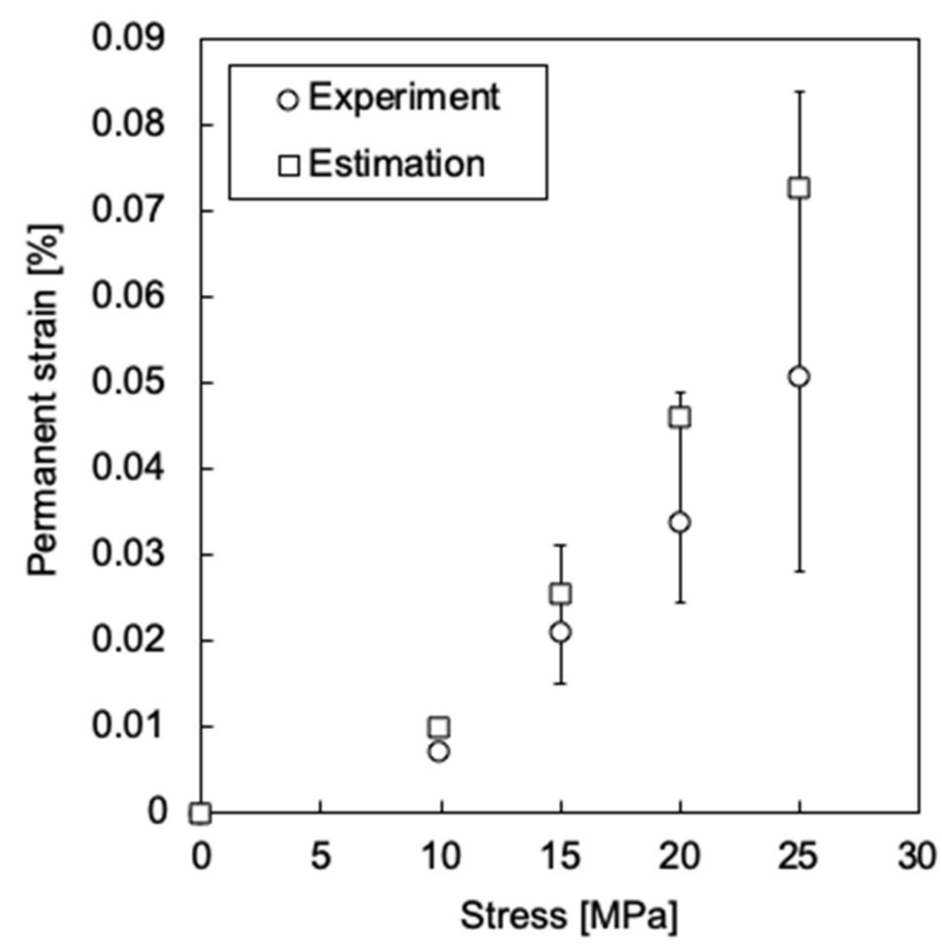

Figure 17. Estimation of permanent strain: circles represent results; squares represent estimations.

To verify these possible reasons, we assessed the dependence of closed crack surface friction and the crack propagation angle by calculating the inelastic strain of each direction, and by using Equations ((5)-(8)). Figure 18 presents a comparison of the estimated inelastic strain of the tensile and compressive direction by changing the frictional coefficient $\mu$. The inelastic strain of the compressive direction increases concomitantly with decreasing $\mu$.

The maximum inelastic strain of the compressive direction is, however, much less than that of the tensile direction. This finding suggests that the frictional coefficient has a small effect on the greater inelastic strain of the tensile direction.

Figure 19 presents a distribution of estimated inelastic strain over the crack angles (hollow, tensile direction; solid, compressive direction; circle, $15 \mathrm{MPa}$; square; $25 \mathrm{MPa}$ ). Regarding $15 \mathrm{MPa}$ peak stress, the inelastic strain of the tensile direction is greater than that of the compressive direction, irrespective of the crack angle. This finding is also confirmed in the case of $25 \mathrm{MPa}$ peak stress, irrespective of the increase in crack length, as shown in Table 1 . Therefore, results suggest that crack propagation and its angle are irrelevant to the greater inelastic strain of tensile direction.

Considering the independence of frictional coefficients, crack propagation and its angle, one can infer by elimination that the greater inelastic strain of the tensile direction seems to result from the difference of the crack opening mode. This indication also supports the fundamental estimation theory of the stress-strain relation, as proposed in Section 3.4, that only the mode II crack opening occurs with a slip during compression, whereas the mixed mode I and II crack opening happens during tension. 


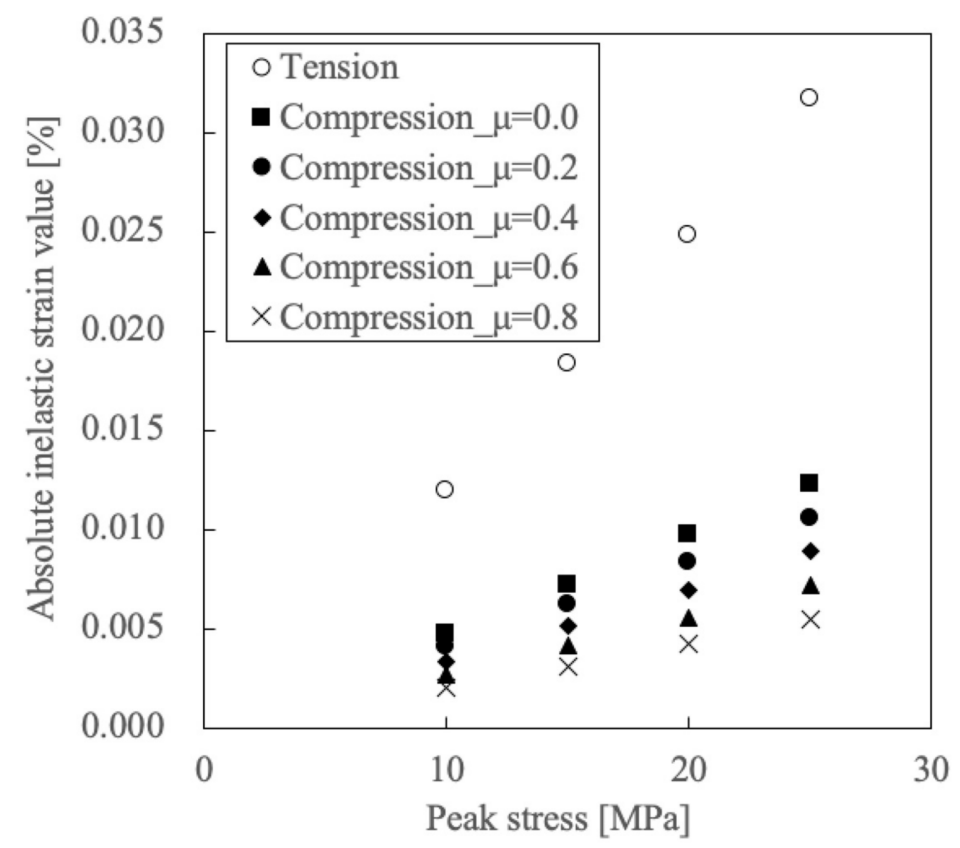

Figure 18. Frictional coefficient effects on the difference of absolute inelastic strains between decomposed tensile and compressive direction of shear strain (hollow-tensile direction inelastic strain; solid-compression; square $-\mu=0.0$; circle $-\mu=0.2$; rhombus $-\mu=0.4$; triangle $-\mu=0.6$; $\mathrm{x}$-mark- $\mu=0.8)$.

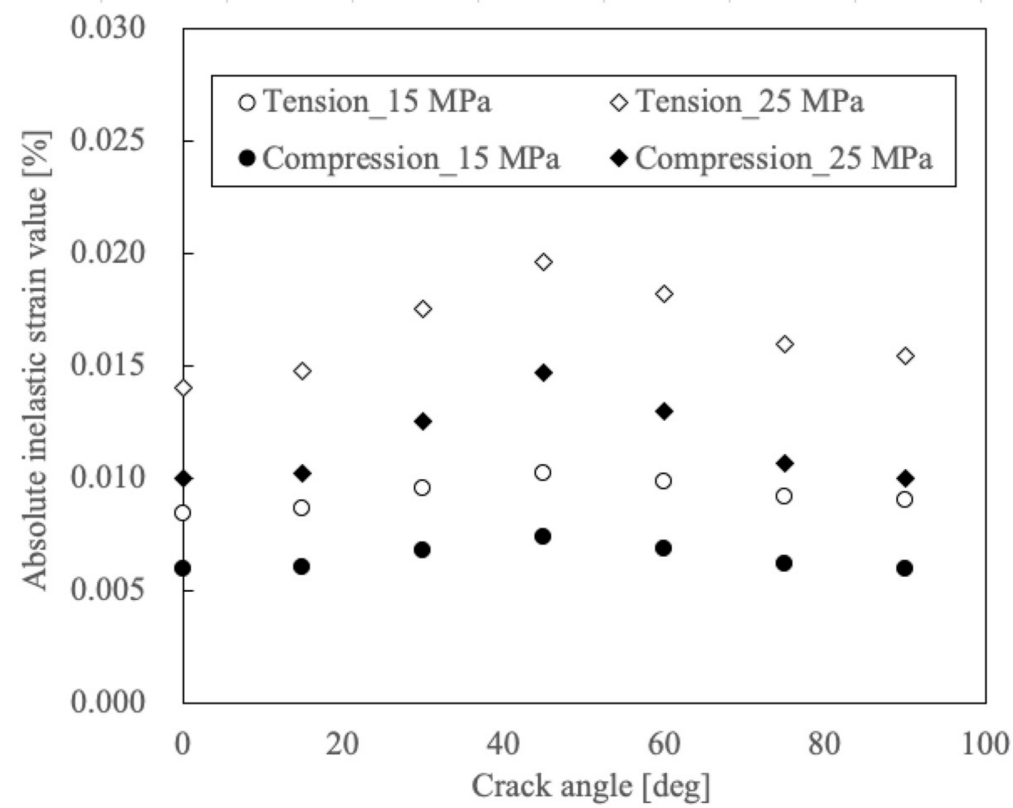

Figure 19. Crack angle effects on the difference of absolute inelastic strains between decomposed tensile and compressive direction of shear strain (hollow-tensile direction inelastic strain; solidcompression; circle_-at $15 \mathrm{MPa}$ peak stress; rhombus—at $25 \mathrm{MPa}$ peak stress).

\section{Conclusions}

This study investigated cumulative damage behavior of the short fiber type $\mathrm{C} / \mathrm{SiC}$ separately using Iosipescu specimens. In addition, a shear damage mechanics model predicting stress-strain relations was proposed.

A stress-strain nonlinear relation was found. Inelastic strain of the tensile direction was greater than that of the compressive direction. Cracks mostly intruded in the boundary 
of the transverse fibers, propagating perpendicularly to the decomposed tensile direction of shear stress.

The proposed shear damage mechanics model succeeded in predicting stress-strain relations and permanent strain of the through-thickness plane, which suggests that shear mechanical properties are predictable from the measured damage characteristics (crack length, number and angle). This model also revealed specific shear deformation behaviors in that the mixed mode I and II crack opening causes the nonlinear stress-strain relation, and that inelastic strain of tensile direction is always greater than that of compressive direction regardless of the friction of closed crack, crack propagation and its angle.

Author Contributions: Conceptualization, methodology, validation, data curation, writing-review and editing, K.G., Y.T. and S.T.; supervision, K.G. and S.T.; formal analysis, investigation, writingoriginal draft preparation, visualization, Y.T. All authors have read and agreed to the published version of the manuscript.

Funding: This research received no external funding.

Acknowledgments: This research was conducted during the doctoral course of SOKENDAI supervised by Ken Goto and Shinsuke Takeuchi.

Conflicts of Interest: The authors declare that they have no conflict of interest.

\section{References}

1. Krenkel, W.; Heidenreich, B.; Renz, R. C/C-SiC Composites for Advanced Friction Systems. Adv. Eng. Mater. 2002, 4, 427-436. [CrossRef]

2. Krenkel, W. Carbon Fiber Reinforced CMC for High-Performance Structures. Int. J. Appl. Ceram. Technol. 2004, 1, 188-200. [CrossRef]

3. El-Hija, H.A.; Krenkel, W.; Hugel, S. Development of C/C-SiC Brake Pads for High-Performance Elevators. Int. J. Appl. Ceram. Technol. 2005, 2, 105-113. [CrossRef]

4. Krenkel, W. Carbon fiber reinforced silicon carbide composite (C/SiC, C/C-SiC). In Handbook of Ceramic Composites; Bansal, P.N., Ed.; Kluwer Academic Publishers: New York, NY, USA, 2005; pp. 117-148.

5. Park, J.; Nishimura, H.; Hayasaka, D.; Yu, J.; Kishimoto, H.; Kohyama, A. Fabrication of short SiC fiber reinforced SiC matrix composites with high fiber volume fraction. Fusion Eng. Des. 2016, 109, 1174-1178. [CrossRef]

6. $\quad$ Enya, K.; Yamada, N.; Imai, T.; Tange, Y.; Kaneda, H.; Katayama, H.; Kotani, M.; Murayama, K.; Naitoh, M.; Nakagawa, T.; et al. High-precision CTE measurement of hybrid C/SiC composite for cryogenic space telescopes. Cryogenics 2012, 52, 86-89. [CrossRef]

7. Evans, A.G.; Zok, F.W.; Mcmeeking, R.M. Fatigue of Ceramic Matrix Composites. Acta Met. Mater 1995, 43, 859-875. [CrossRef]

8. Gasser, A.; Ladeveze, P.; Peres, P. Damage modelling for a laminated ceramic composite. Mater. Sci. Eng. 1998, A250, $249-255$. [CrossRef]

9. Tobata, Y.; Takeuchi, S.; Goto, K. Cumulative Damage Mechanism of Short Fiber type C/SiC under Compression. J. Eur. Ceram. Soc. 2021, 41, 185-193. [CrossRef]

10. Tobata, Y. Cumulative Damage Mechanics of Short Fiber Reinforced Ceramic Matrix Composites. J. Eur. Ceram. Soc. 2021, 41, 185-193. [CrossRef]

11. Beyerle, D.S.; Spearing, S.M.; Evans, A.G. Damage Mechanisms and the Mechanical Properties of a Laminated 0/90 Ceramic/Matrix Composite. J. Am. Ceram. Soc. 1992, 75, 3321-3330. [CrossRef]

12. Shi, Y.; Tushtev, K.; Koch, D. Characterization of Mechanical Properties under Shear Load of a Short-Carbon-Fiber-Reinforced C/SiC Ceramic. J. Ceram. Sci. Technol. 2015, 6, 183-190.

13. Jain, N.; Koch, D. Prediction of Failure in Ceramic Matrix Composites Using Damage-Based Failure Criterion. J. Compos. Sci. 2020, 4, 183. [CrossRef]

14. Barbero, E.J. Finite Element Analysis of Composite Materials Using ANSYS ${ }^{\circledR}$; CRC Press: Boca Raton, FL, USA, 2013.

15. Tsai, S.W.; Wu, E.M. A general theory of strength for anisotropic materials. J. Compos. Mater. 1972, 5, 58-80. [CrossRef]

16. Li, J.; Jiao, G.; Wang, B.; Li, L.; Yang, C. Damage characteristics and constitutive modeling of the 2D C/SiC composite: PartIIMaterial and numerical implementation. Chin. J. Aeronaut. 2015, 28, 314-326. [CrossRef]

17. Mevissen, F.; Meo, M. A Review of NDT/Structural Health Monitoring Techniques for Hot Gas Components in Gas Turbines. Sensors 2019, 19, 711. [CrossRef] [PubMed]

18. Santhosh, U.; Ahmad, J.; Ojard, G.; Miller, R.; Gowayed, Y. Deformation and damage modeling of ceramic matrix composites under multiaxial stresses. Compos. Part B 2016, 90, 97-106. [CrossRef]

19. Inoue, R.; Yang, J.M.; Kakisawa, H.; Kagawa, Y. Mode I fracture toughness of short carbon fiber-dispersed SiC matrix composite fabricated by melt infiltration process. Ceram. Int. 2013, 39, 8341-8346. [CrossRef] 
20. Inoue, R.; Yang, J.M.; Kakisawa, H.; Kagawa, Y. Mixed-Mode Fracture Criterion of Short Carbon Fiber-Dispersed SiC Matrix Composite. J. Ceram. Sci. Technol. 2017, 8, 223-232.

21. Inoue, R.; Arai, Y.; Kubota, Y.; Goto, K.; Kogo, Y. Oxidation behavior of carbon fiber-dispersed ZrB2-SiC-ZrC triple phase matrix composites in an oxyhydrogen torch environment. Ceram. Int. 2018, 44, 8387-8396. [CrossRef]

22. Ashby, M.F.; Hallam, S.D. The Failure of Brittle Solids Containing Small Cracks under Compressive Stress States. Acta Metal. 1986, 34, 497-510. [CrossRef]

23. Horii, H.; Nemat-Nasser, S. Brittle failure in compression: Splitting, faulting and brittle-ductile transition. Philos. Trans. R. Soc. London. Ser. A Math. Phys. Sci. 1986, 319, 337-374. 